University of Wollongong

Research Online

Faculty of Engineering and Information

Faculty of Engineering and Information

Sciences - Papers: Part A

Sciences

$1-1-2016$

\title{
Effect of deformation on microstructure and mechanical properties of dual phase steel produced via strip casting simulation
}

Zhiping Xiong

University of Wollongong, zx868@uowmail.edu.au

Andrii Kostryzhev

University of Wollongong, andrii@uow.edu.au

Nicole Stanford

Centre for Material and Fibre Innovation, Deakin University, stanford@deakin.edu.au

Elena V. Pereloma

University of Wollongong, elenap@uow.edu.au

Follow this and additional works at: https://ro.uow.edu.au/eispapers

Part of the Engineering Commons, and the Science and Technology Studies Commons

Research Online is the open access institutional repository for the University of Wollongong. For further information contact the UOW Library: research-pubs@uow.edu.au 


\title{
Effect of deformation on microstructure and mechanical properties of dual phase steel produced via strip casting simulation
}

\begin{abstract}
The strip casting is a recently appeared technology with a potential to significantly reduce energy consumption in steel production, compared to hot rolling and cold rolling. However, the quantitative dependences of the steel microstructure and mechanical properties on strip casting parameters are unknown and require investigation. In the present work we studied the effects of strain and interrupted cooling temperature on microstructure and mechanical properties in conventional dual phase steel (0.08C-0.81Si-1.47Mn-0.03Al wt\%). The strip casting process was simulated using a Gleeble 3500 thermo-mechanical simulator. The steel microstructures were studied using optical, scanning and transmission electron microscopy. Mechanical properties were measured using microhardness and tensile testing. Microstructures consisting of $40-80 \%$ polygonal ferrite with remaining martensite, bainite and very small amount of Widmanstätten ferrite were produced. Deformation to 0.17-0.46 strain at 1050 . ${ }^{\circ} \mathrm{C}$ refined the prior austenite grain size via static recrystallisation, which led to the acceleration of ferrite formation and the ferrite grain refinement. The yield stress and ultimate tensile strength increased with a decrease in ferrite fraction, while the total elongation decreased. The improvement of mechanical properties via deformation was ascribed to dislocation strengthening and grain boundary strengthening.
\end{abstract}

\section{Keywords}

effect, deformation, microstructure, mechanical, casting, properties, simulation, dual, phase, steel, produced, via, strip

\section{Disciplines}

Engineering | Science and Technology Studies

\section{Publication Details}

Xiong, Z. P., Kostryzhev, A. G., Stanford, N. \& Pereloma, E. V. (2016). Effect of deformation on microstructure and mechanical properties of dual phase steel produced via strip casting simulation. Materials Science and Engineering A: Structural Materials: Properties, Microstructure and Processing, 651 291-305. 


\title{
Development of a novel phase change emulsion material for cooling systems
}

\author{
Jingjing Shao ${ }^{a,}$, Jo Darkwa $^{\mathrm{a}}$ and Georgios Kokogiannakis ${ }^{\mathrm{b}}$ \\ ${ }^{a}$ Department of Architecture and Built Environment, Faculty of Engineering, University of Nottingham, \\ University Park, NG7 2RD Nottingham, UK \\ ${ }^{\mathrm{b}}$ Sustainable Buildings Research Centre, University of Wollongong, Wollongong NSW 2522, Australia
}

Correspondence information:

Corresponding author: Jingjing SHAO, PhD candidate

Add: Department of Architecture and Built Environment, University of Nottingham, University Park,

Nottingham, UK, NG7 2RD

Tel: +44 (0) 7436993953

Email: jingjing.shao@ nottingham.edu.cn 


\section{Development of a novel phase change emulsion material for cooling systems}

\section{Nomenclature}

\section{$\mathrm{T}_{\mathrm{m}} \quad$ Melting point}

$\mathrm{C}_{\mathrm{p}} \quad$ Specific heat capacity

$\eta \quad$ Viscosity

$\varphi \quad$ Volume fraction

$\mathrm{X}$ Weight fraction

\section{Subscripts}

e Emulsion

$\mathrm{p} \quad$ Paraffin

w Water

17

being encouraged.

$$
\text { Water }
$$

Jingjing Shao ${ }^{\mathrm{a}, 1}$ Jo Darkwa $^{\mathrm{a}}$ and Georgios Kokogiannakis ${ }^{\mathrm{b}}$

${ }^{\mathrm{b}}$ Sustainable Buildings Research Centre, University of Wollongong, Wollongong NSW 2522, Australia

\section{Abstract}

In this paper, a novel phase change emulsion material (PCE-10) consisting of an organic segregation but the viscosity was found to be much higher than that of water.

$\begin{array}{ll}\Delta \mathrm{h}_{\mathrm{f}} & \text { Latent heat capacity } \\ \Delta \mathrm{h}_{\mathrm{e}} & \text { Heat storage capacity } \\ \Delta \mathrm{h}_{\mathrm{s}} & \text { Sensible heat capacity } \\ \mathrm{T} & \text { Temperature } \\ \mathrm{V} & \text { Volume }\end{array}$

S surfactant

separate Separated phase

\footnotetext{
${ }^{1}$ Corresponding author Tel.: +44 (0)7436993953; E-mail:epxjs5 @ nottingham.ac.uk
} 


\section{Introduction}

19 Over last few years, chilled water system powered by environmental friendly energy resources has attracted great attention. However, the availability of renewable energy, such as solar and wind, is uncontinuous. Efficient thermal energy storage (TES) for reducing the mismatch between energy supply and demand for cooling applications is necessary [1]. In addition, chilled water circulation pumps are responsible for roughly $15 \%-30 \%$ of the overall energy consumption [2].

To this end, some researchers have suggested replacing water with phase change emulsions (PCMEs) as cooling media which consist of phase change materials (PCMs) and carrier fluids such as water. This is based on the fact that, they possess higher heat capacities and therefore capable of reducing volume flow rates and energy consumption in pumps [4]. PCMEs could also act as the thermal storage material simultaneously, reducing the mismatch between energy supply and demand for cooling applications [5].

However, most of the commercially available PCMEs do experience high levels of subcooling temperatures which tend to affect the performance of refrigeration equipment. For instance Huang et al. [6] observed poor performance in a refrigeration system at high subcooling temperatures of $4.3 \mathrm{~K}$ and $14.7 \mathrm{~K}$ when tetradecane/water and hexadecane/water PCMEs were used respectively. Royon and Guiffant [7] also observed poor performance at a sub-cooling temperature of $5.6 \mathrm{~K}$ when aliphatic hydrocarbons-water emulsion was tested. Another main barrier affecting the application of PCMEs is the thermal instability that they experience after a period of usage and storage. Typically, air conditioning systems operate for a period of six months each year [8]. Therefore the PCMEs should be able to remain stable for at least six months and also not experience any temperature stratification when the air conditioning systems are in operation. Literature review shows that most of the currently available PCMEs fail to meet these requirements. For example, the emulsion 
developed by $\mathrm{Xu}$ et al. [9] with tetradecane and water was stable for only 40-50s. The sample tested by Schalbart et al. [10] achieved a short period of storage stability at room temperature. Vilasau et al. [11] also tested the freeze-thaw stability of a paraffin emulsion and achieved stability for only 5 cycles. The PCME developed by Huang [12] experienced instability after a short storage period of one month and 100 melting/freezing thermal cycling.

This study is therefore intended to develop a novel phase change emulsion material that is capable of overcoming these technical barriers.

\section{Development of PCME}

\subsection{Selection of Paraffin}

According to Huang et al [12], selection of PCMEs for air conditioning application should be based on properties such as high heat capacity, low sub-cooling temperature, long term storage stability and low viscosity. Paraffin materials such as tetradecane $\mathrm{CH}_{3}-\left(\mathrm{CH}_{2}\right)_{12}-\mathrm{CH}_{3}$ $\left(\mathrm{T}_{\mathrm{m}}=5.8^{\circ} \mathrm{C}, \Delta \mathrm{h}_{\mathrm{f}}=227 \mathrm{~kJ} \cdot \mathrm{kg}^{-1}\right)$ and pentadecane $\mathrm{CH}_{3}-\left(\mathrm{CH}_{2}\right)_{13}-\mathrm{CH}_{3}\left(\mathrm{~T}_{\mathrm{m}}=9.9^{\circ} \mathrm{C}, \Delta \mathrm{h}_{\mathrm{f}}=206 \mathrm{~kJ} \cdot \mathrm{kg}^{-1}\right)$ are typical pure organic PCMs which may be combined with water to form PCMEs for cooling applications within a phase transition temperature range of $7-12^{\circ} \mathrm{C}$. However, due to the relatively high cost of pure PCM, commercially available blended paraffin such as RT6 and RT10, are widely used for practical application. It should be noted that since the RT series are mixtures of different paraffin their melting/freezing processes do not occur at specific temperatures but rather over a temperature range.

The properties of RT10 and RT6 are listed in Tab. 1 [13]. For this development, RT10 was selected as the core material because its melting/freezing temperature falls within the working temperature of air conditioning systems. It also has higher heat of fusion and lower subcooling temperature than RT6.

66

67 
68

69

\begin{tabular}{ccc}
\multicolumn{2}{c}{ Table 1: Thermo-physical properties of RT6 and RT10 [14] } \\
\hline & RT6 & RT10 \\
\hline Density $(\mathrm{g} / \mathrm{cm} 3)$ & 0.73 & 0.8 \\
Melting temperature range $\mathrm{T}_{\mathrm{e}}\left({ }^{\circ} \mathrm{C}\right)$ & $2.8-8.3$ & $2.3-12$ \\
Peak melting point $\mathrm{T}_{\mathrm{p}, \mathrm{m}}\left({ }^{\circ} \mathrm{C}\right)$ & 7 & 9 \\
Freezing temperature range $\mathrm{T}_{\mathrm{p}, \mathrm{f}}\left({ }^{\circ} \mathrm{C}\right)$ & $3.5-7.2$ & $5.1-11.8$ \\
Subcooling $\left({ }^{\circ} \mathrm{C}\right)$ & 1.1 & 0.2 \\
Heat of fusion $\left(\mathrm{kJ} \mathrm{kg}^{-1}\right)$ & 132 & 135 \\
Conductivity $\left(\mathrm{W} \mathrm{m}{ }^{-1} \mathrm{~K}^{-1}\right)$ & 0.19 & 0.21 \\
Viscosity $(\mathrm{mPas})$ & 18 & 22 \\
\hline
\end{tabular}

70

\subsubsection{Determination of Paraffin Concentration}

PCMEs are expected to have at least heat capacity of twice as high as that of water [14]. In the temperature range of $7-12^{\circ} \mathrm{C}$, water has a sensible heat capacity of $20.9 \mathrm{~kJ} \cdot \mathrm{kg}^{-1}$, and therefore the PCME should have at least a heat capacity of $40 \mathrm{~kJ} \cdot \mathrm{kg}^{-1}$.

In the temperature range from $\mathrm{T}_{1}$ to $\mathrm{T}_{2}$, total heat storage capacity of PCME $\Delta \mathrm{h}_{\mathrm{e}}$ is the sum of latent heat capacity of the emulsion $\Delta \mathrm{h}_{\mathrm{f}, \mathrm{e}}$, the sensible heat capacity of water $\Delta \mathrm{h}_{\mathrm{s}, \mathrm{w}}$ and that of paraffin $\Delta \mathrm{h}_{\mathrm{s}, \mathrm{p}}$ as follows [15]:

$$
\Delta h_{\mathrm{e}}=\Delta h_{\mathrm{f}, \mathrm{e}}+\Delta h_{\mathrm{s}, \mathrm{w}}+\Delta h_{\mathrm{s}, \mathrm{p}}=X_{p} \Delta h_{\mathrm{f}, \mathrm{p}}+X_{W} C_{p, W}\left(T_{2}-T_{1}\right)+X_{p} C_{p, p}\left(T_{2}-T_{1}\right)
$$

Where, $X_{w}$ and $X_{p}$ are the weight fractions of paraffin and water, $\Delta h_{f, p}$ is the heat of fusion of paraffin in the temperature range of $T_{1}$ to $T_{2} \cdot C_{p, w}$ and $C_{p, p}$ are the specific heat capacity of water and the average specific heat capacity of the paraffin, respectively.

In the temperature range of $7-12^{\circ} \mathrm{C}, 25 \mathrm{wt} \%$ PCME has a total heat capacity of $41 \mathrm{~kJ} \cdot \mathrm{kg}^{-1}$, which is almost 2 times as high as that of water. As indicated in Equ. 1, the heat capacity of PCME is proportional to concentration of paraffin [12]. For paraffin concentration lower than $25 \mathrm{wt} \%$, the total heat capacity of the sample would fall short of the above criteria hence the limit for this case..

Appropriate PCME for application in air conditioning systems should also have low viscosity to ensure an acceptable level of pressure drop in pumps. Zhao [16] proposed the following equation for predicting the kinematic viscosity of a two liquid mixture. 
91 Where, $\eta$ and $\eta_{w}$ are the viscosities of emulsion and water respectively, $\varphi$ is the volume

92 fraction of oil phase and $\mathrm{k}$ is a constant which equals to 7 when $\varphi \leq 0.74$.

For PCM concentrations over $35 \mathrm{wt} \%$, the viscosity of emulsions will be 15 times that of

94

103

\begin{tabular}{cccccc}
\multicolumn{6}{c}{ Table 2: Physical properties of 25-35wt\% of RT10/Water emulsion } \\
\hline $\begin{array}{c}\text { Paraffin } \\
(\text { RT 10) } \\
\begin{array}{c}\text { Concentration } \\
(\mathrm{wt} \%)\end{array}\end{array}$ & $\begin{array}{c}\text { Heat of fusion } \\
\left(\mathrm{kJ} \cdot \mathrm{kg}^{-1}\right)\end{array}$ & $\begin{array}{c}\text { Heat storage } \\
\text { capacity } \\
\left(\mathrm{KJ} \cdot \mathrm{kg}^{-1}\right)\end{array}$ & $\begin{array}{c}\text { Heat storage ratio } \\
\text { PCME-to water ratio }\end{array}$ & $\begin{array}{c}\text { Viscosity } \\
(\mathrm{mPas})\end{array}$ & $\begin{array}{c}\text { Conductivity } \\
\left(\mathrm{W} \cdot \mathrm{m}^{-1} \cdot \mathrm{K}^{-1}\right)\end{array}$ \\
\hline 25 & 30.8 & 42 & 1.99 & 21 & 0.40 \\
30 & 31.2 & 42.2 & 2.01 & 30 & 0.34 \\
35 & 31.5 & 42.6 & 2.03 & 36 & 0.33 \\
$0 \%$ & - & 21 & - & 1.3 & 0.60 \\
\hline
\end{tabular}
water. PCME is required to have a low viscosity for applications in pump systems. Thus, the paraffin weight fraction should not be more than $35 \mathrm{wt} \%$ for this case.

Based on the theoretical analysis, different samples of emulsions consisting of $25 \mathrm{wt} \%$, $30 \mathrm{wt} \%$ and $35 \mathrm{wt} \%$ concentration levels of paraffin were prepared for evaluation as summarised in Tab. 2. Analysis of the results shows that the sample containing $25 \mathrm{wt} \%$ of paraffin is the most appropriate type with the acceptable level of heat of fusion and the highest thermal conductivity. It also has the lowest viscosity value and therefore suitable for reducing energy consumption in pumping systems.

2

104 
111 obtain an optimum emulsification. HLB values can range from 0 to 20 depending upon the

112 composition of the surfactant. As the HLB value increases, the surfactant becomes more

113 hydrophilic and less lipophilic. In a situation where two or more surfactants are mixed

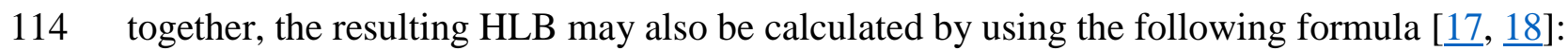

$$
H L B=X_{S, 1} \times H L B_{S, 1}+X_{S, 2} \times H L B_{S, 2}+\ldots \ldots
$$

\subsubsection{Determination of RHLB}

117 For the required HLB of oil phase, a series of emulsions will be made. Each emulsion will

118 have the same amount of oil phase, water and surfactants but at a different HLB value. Any

119 pair of non-ionic surfactants can be used to determine the appropriate values of HLB but one

120 of them should have a low HLB number $(<6)$ and the other a high HLB number $(>14)$. In this

121 study, two types of surfactants Brij $52(\mathrm{HLB}=5)$ and Tween $20(\mathrm{HLB}=16.7)$ were selected to

122 produce five different emulsions and Eq. (3) was used to obtain their corresponding HLB

123 values. The blended samples were then kept in test tubes and observed over a period of time

124 in order to evaluate their chemical stability levels. As summarised in Tab. 3 sample No. 3

125 achieved the longest period of chemical stability. Based on this result, the HLB requirement

126 of the system is closest to 10.9 .

127

128

Table 3: Required HLB values

\begin{tabular}{ccccc}
\hline \multirow{2}{*}{ Sample No. } & \multicolumn{2}{c}{ Surfactants } & Calculated HLB & $\begin{array}{c}\text { Chemical separation } \\
\text { period } \\
\text { (min) }\end{array}$ \\
\hline 1 & Brij 52 & Tween 20 & 5.0 & $\leq 5$ \\
2 & $100 \%$ & $0 \%$ & 9.7 & $\leq 90$ \\
3 & $60 \%$ & $40 \%$ & 10.9 & $>90$ \\
4 & $50 \%$ & $50 \%$ & 12.0 & $\leq 30$ \\
5 & $40 \%$ & $60 \%$ & 16.7 & $\leq 5$ \\
\hline
\end{tabular}




\subsubsection{Optimised blend of surfactants}

131 Even though sample No. 3 appears to be the best candidate, it may not be the best

132 combination as their chemical structures can affect the stability of the emulsions. For instance,

133 surfactants with longer hydrocarbon tails are more effective in stabilizing dispersions than

134 those with shorter carbon chain lengths [19]. For these reasons different types of non-ionic

135 surfactant and an ionic surfactant (HTAB) with mixture HLB values around 10.9 were

136 blended and tested for stability after 48-hour storage period. This was assessed through their

137 separation rates by dividing the sum of the volume of water separated in the test tubes plus

138 that of paraffin $\left(V_{\text {seperate }}=V_{w}+V_{p}\right)$ by the total sample volume $\left(\mathrm{V}_{\text {total }}=V_{w}+V_{p}+V_{e}\right)$. This is

139 explained in Fig. 1 and expressed mathematically in Eq. (4) as:

140

$$
V \%=V_{\text {seperate }} / V_{\text {total }} \times 100 \%=V_{w}+V_{p} / V_{w}+V_{p}+V_{e} \times 100 \%
$$

141 Analysis of the results in Tab. 4 shows that the blend of Tween 60 and Brij 52 surfactants

142 achieved the highest level of stability without any sign of separation after the monitored

143 period and was attributed to their combined long hydrocarbon tails of 18 and 16 carbon atoms

144 respectively in the alkyl chain. This is further supported by previous research [19] which

145 indicated that long hydrocarbon tail can also act as nucleation centre for activating

146 crystallization and for reducing sub-cooling. To this end, 60\% Tween60 and 40\% Brij52

147 surfactants were selected for the optimum surfactant blend.

148 


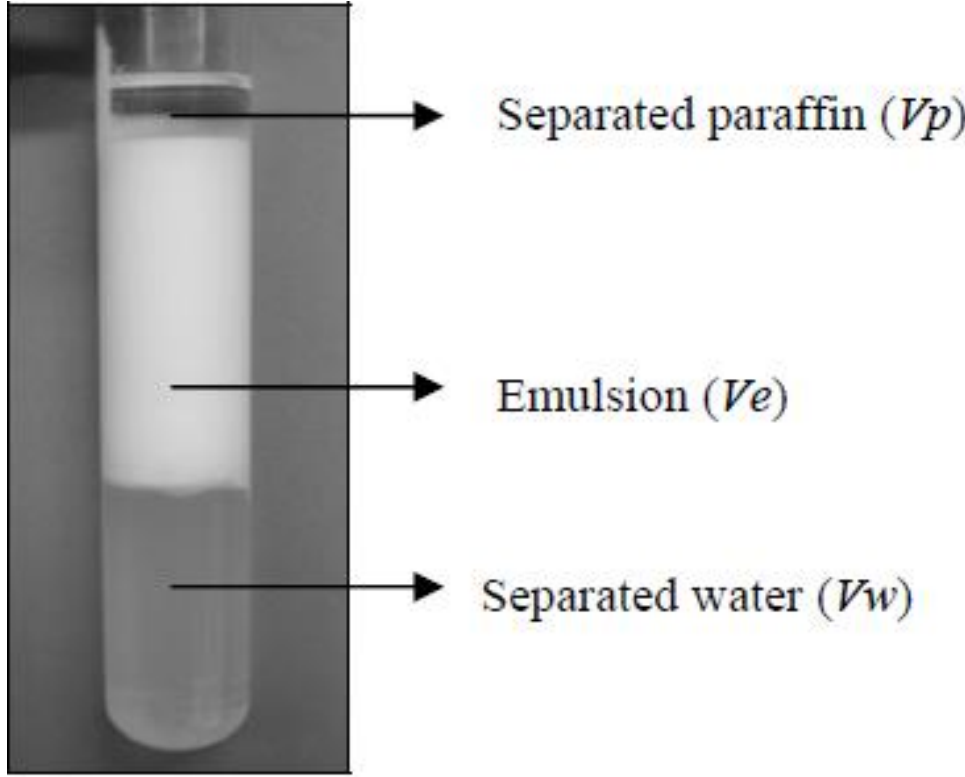

Figure 1: Emulsion separation

Table 4: Optimised surfactant blends

\begin{tabular}{ccccc}
\hline \multirow{2}{*}{ Sample No. } & \multicolumn{2}{c}{ Surfactant types } & Calculated HLB & $\begin{array}{c}\text { Separation } \\
\text { Rate }\end{array}$ \\
& Blends of surfactants & \%wt ratio & 11.0 & $60 \%$ \\
6 & Brij 35/Brij 52 & $50: 50$ & 10.9 & $60 \%$ \\
7 & HTAB/Brij 52 & $55: 45$ & 10.9 & 0 \\
9 & Tween 60/Brij 52 & $60: 40$ & 10.9 & $20 \%$ \\
10 & Tween 20/Brij 52 & $50: 50$ & 10.5 & $50 \%$ \\
\hline
\end{tabular}

\subsubsection{Concentration of Surfactant}

Regarding the level of concentration of surfactant, Wang et al [20] suggested that 10-25\% of dispersed phase of surfactant would be effective in ensuring the stability of PCME under either storage or mechanical-thermal cycling condition. However, other investigations revealed that, concentration level should not be lower than $5 \mathrm{wt} \%$ of total emulsion mixture $[\underline{21}, \underline{22}]$.

In order to establish the appropriate level of concentration, 25\% RT10 and water emulsions with different mass fractions of the blended surfactant (5-20\% of oil phase) were prepared and tested for storage stability over a period of 72 hours. As summarised in Tab. 5, 
sample No. 4 achieved the best stability result with no sign of chemical separation whereas samples No. 1-3 suffered from rapid chemical separation of various components before the

167 considered unsuitable for testing.

168

Table 5: Evaluation test results for blended surfactants

\begin{tabular}{|c|c|c|c|c|c|c|}
\hline \multirow{2}{*}{$\begin{array}{l}\text { Sample } \\
\text { No. }\end{array}$} & \multirow{2}{*}{$\begin{array}{c}\text { RT10 } \\
\text { Concentration }\end{array}$} & \multirow{2}{*}{$\begin{array}{c}\text { Water } \\
\text { Concentration }\end{array}$} & \multicolumn{2}{|c|}{$\begin{array}{l}\text { Blended surfactant } \\
\text { Tween 60/Brij 52(3:2) }\end{array}$} & \multirow{2}{*}{$\begin{array}{c}\text { Chemical } \\
\text { separation } \\
\text { period } \\
(\mathrm{min})\end{array}$} & \multirow{2}{*}{$\begin{array}{l}\text { Separation } \\
\text { rate at } 72 \mathrm{hr}\end{array}$} \\
\hline & & & $\begin{array}{c}\text { Concentration } \\
\text { of surfactant }\end{array}$ & $\begin{array}{c}\text { Surfactant/oil } \\
\text { ratio }\end{array}$ & & \\
\hline 1 & $25 \%$ & $74.75 \%$ & $1.25 \%$ & $5 \%$ & $<6$ & $60 \%$ \\
\hline 2 & $25 \%$ & $73 \%$ & $2 \%$ & $8 \%$ & $\leq 20$ & $45 \%$ \\
\hline 3 & $25 \%$ & $72.5 \%$ & $2.5 \%$ & $10 \%$ & $\leq 48$ & $50 \%$ \\
\hline 4 & $25 \%$ & $71.25 \%$ & $3.75 \%$ & $15 \%$ & $>72$ & 0 \\
\hline 5 & $25 \%$ & $70 \%$ & $5 \%$ & $20 \%$ & $\begin{array}{c}\text { Not } \\
\text { applicable }\end{array}$ & $\begin{array}{c}\text { Not } \\
\text { applicable }\end{array}$ \\
\hline
\end{tabular}

\subsection{Preparation of PCME}

172 Phase change emulsion was prepared by the so-called "mixing film synthesis". All the

173 constituents were initially weighted by a precision weighing scale as given in Tab. 6. The

174 lipophilic surfactant Brij 52 was then dissolved in RT10 (Mixture A) while hydrophilic

175 surfactant Tween 60 was mixed with deionized water (Mixture B). The mixtures were heated

176 separately to about $50-55^{\circ} \mathrm{C}$ before being added together and pre-emulsified using a

177 magnetic hot plate stirrer at a speed of $500 \mathrm{rpm}$ and at $50^{\circ} \mathrm{C}$ for 15 minutes. Final

178 emulsification was carried out by passing the coarse emulsion through a rotor-stator machine

179 type ULTRA-TURRAX T18 at an emulsifying speed of 7200rpm for another 45 minutes.

180 The developed sample which was named as PCE-10 could be described as a white milky Oil-

181 in-Water emulsion. 
183

Table 6: Composition of PCME

\begin{tabular}{cc}
\hline Components & Wt\% \\
\hline RT10 & 25.0 \\
Tween 60 & 2.25 \\
Brij 52 & 1.5 \\
Water & 71.25 \\
\hline
\end{tabular}

184

185 3. Characterisation of developed emulsion (PCE-10)

\section{$186 \quad 3.1 \quad$ Particle Sizing}

187 Particle sizing and their distribution profiles are important parameters for specifying 188 emulsions. Normally, dispersions with smaller particle sizes represent increased stability than

189 those with coarse droplets. On the other hand, viscosity generally increases significantly with

190 smaller particle sizes for a given mass or volume concentration in the dispersed phase. This is

191 confirmed by Schramm et al. [23] which reported that the size and characteristics of particles

192 do affect the stability, viscosity and thermal properties of emulsions. In this regard, a laser

193 particle size analyser was used to establish the size of the PCE-10 and as a reference for the

194 stability test. As presented in Fig. 2, the mean particle size was obtained as $3.14 \mu \mathrm{m}$.

195

196

197

198

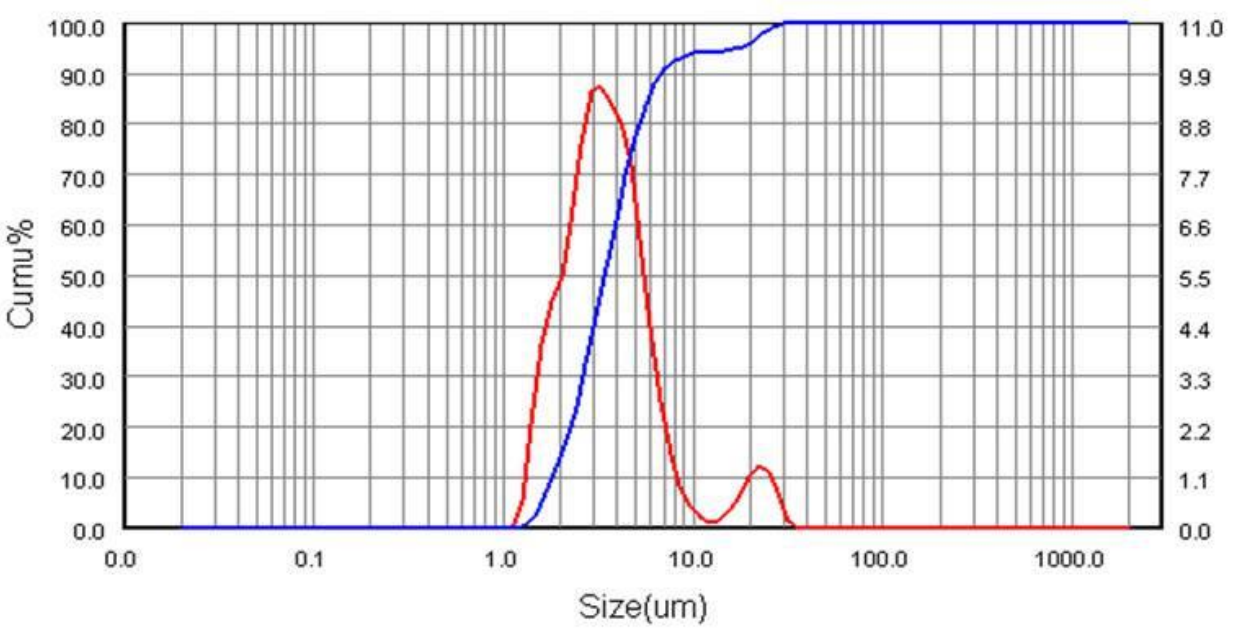

\begin{tabular}{|c|c|}
\hline Diam um & Percent \\
\hline 1.179 & 0.00 \\
\hline 1.712 & 7.36 \\
\hline 2.486 & 25.63 \\
\hline 3.611 & 54.38 \\
\hline 5.245 & 80.30 \\
\hline 7.617 & 91.83 \\
\hline 11.060 & 94.10 \\
\hline 16.060 & 94.71 \\
\hline 23.330 & 97.80 \\
\hline 33.890 & 100.00 \\
\hline
\end{tabular}

Figure 2: Laser Particle sizing of PCE-10 


\subsection{Thermal Conductivity}

200 The thermal conductivity of the sample was determined with a KD2 Pro Thermal

201 Properties Analyser, which has the ability to test liquid samples with accuracy of $\pm 5 \%$. After 202 repeated tests the average thermal conductivity of the PCE-10 was obtained as $0.4 \mathrm{~W} \cdot \mathrm{m}^{-1} \cdot \mathrm{K}^{-1}$ 203 at a temperature of $25^{\circ} \mathrm{C}$ as summarised in Tab. 7.

Table 7: Thermal Conductivity Results

\begin{tabular}{ccc}
\hline Test No. & $\begin{array}{c}\text { Temperature } \\
\left({ }^{\circ} \mathrm{C}\right)\end{array}$ & $\begin{array}{c}\text { Thermal Conductivity } \\
\left(\mathrm{W} \cdot \mathrm{m}^{-1} \cdot \mathrm{K}^{-1}\right)\end{array}$ \\
\hline 1 & 24.94 & 0.409 \\
2 & 25.00 & 0.406 \\
3 & 25.22 & 0.400 \\
Average & 25.11 & 0.403 \\
\hline
\end{tabular}

206

\subsection{Phase Transition Temperature and Heat Capacity}

208 The phase change temperature and the heat of fusion tests were conducted on 5mg sample 209 of the PCE-10 with a Differential Scanning Calorimetry (DSC) apparatus type EXSTAR SII

210 DSC6220 at a scanning rate of $1^{\circ} \mathrm{C} \cdot \mathrm{min}^{-1}$. DSC enables heat associated with flow in a sample

211 to be evaluated as a function of temperature. This may be achieved by recording the

212 difference in heat flow between a sample and a reference material as a function of

213 temperature as expressed mathematically in Eq. 5 [24].

$$
\frac{d H}{d t}=\left(\frac{d H}{d t}\right)_{\text {sample }}-\left(\frac{d H}{d t}\right)_{\text {reference }}
$$

As presented in Fig. 3, an average value for the heat of fusion was obtained as $30.5 \mathrm{~kJ} \cdot \mathrm{kg}^{-1}$

$216\left(\Delta \mathrm{h}_{\mathrm{f}, \mathrm{p}}\right)$ within a temperature range of $4{ }^{\circ} \mathrm{C}\left(\mathrm{T}_{\mathrm{e}}\right)$ and $11.94^{\circ} \mathrm{C}\left(\mathrm{T}_{\mathrm{c}}\right)$. Now by using Eq. (1), the

217 heat storage capacity was calculated as $60.5 \mathrm{~kJ} \cdot \mathrm{kg}^{-1}$ which is 1.8 times of water i.e. 33.4

$218 \mathrm{~kJ} \cdot \mathrm{kg}^{-1}$ within the same temperature range. 


\section{3}

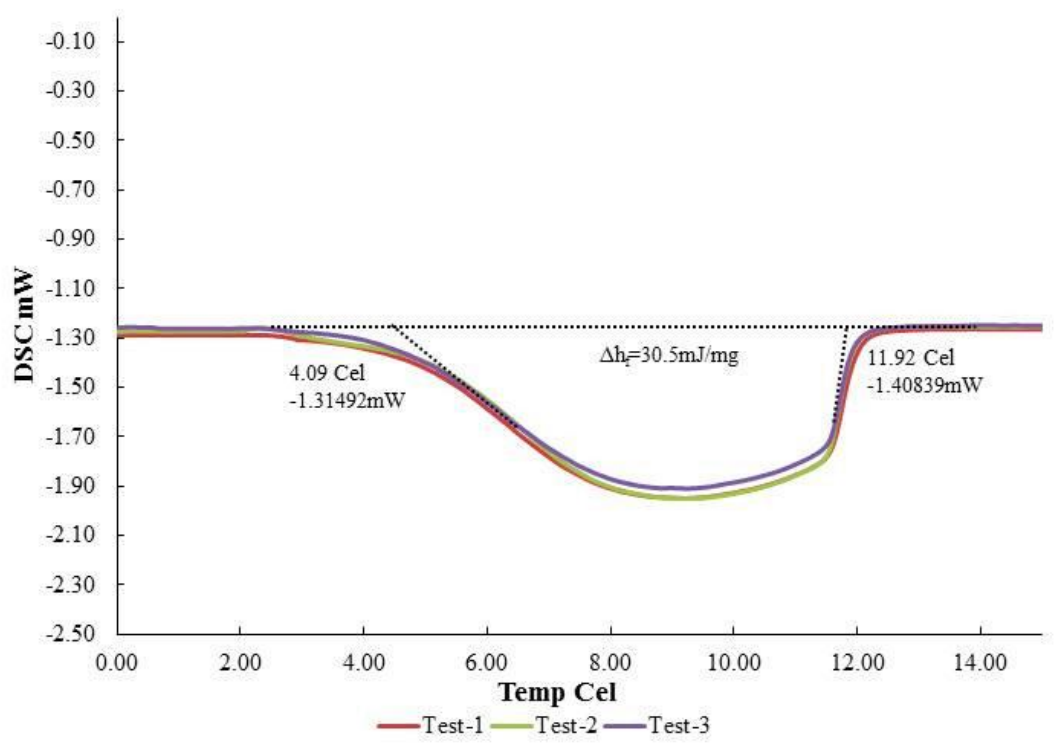

Figure 3: DSC curves of PCE-10

\subsection{Sub-cooling temperature}

Sub-cooling lowers the crystallization temperature of a liquid or a gas, thus latent heat is released at a lower temperature or in a wider temperature range [25]. A large sub-cooling temperature is therefore not acceptable because it would enlarge the operating temperature range of a cooling system and thus affects its performance.

The sub-cooling test was conducted with the T-history method which is normally used in measuring the thermal properties of bulk materials [26]. As demonstrated in Fig. 4, one of the test tubes was filled with PCM and the other with a reference material, usually water, due to its well-known thermo-physical properties. The tubes were then preheated above the melting temperature of the PCM and then simultaneously exposed to the ambient temperature to obtain the temperature history ( $\mathrm{T}$ versus $\mathrm{t}$ ) curves. A typical T-history curve of PCM with sub-cooling is as presented in Fig. 5. The $\Delta \mathrm{T}_{\mathrm{m}}\left(=\mathrm{T}_{\mathrm{e}}-\mathrm{T}_{\mathrm{c}}\right)$ is the sub-cooling degree. 


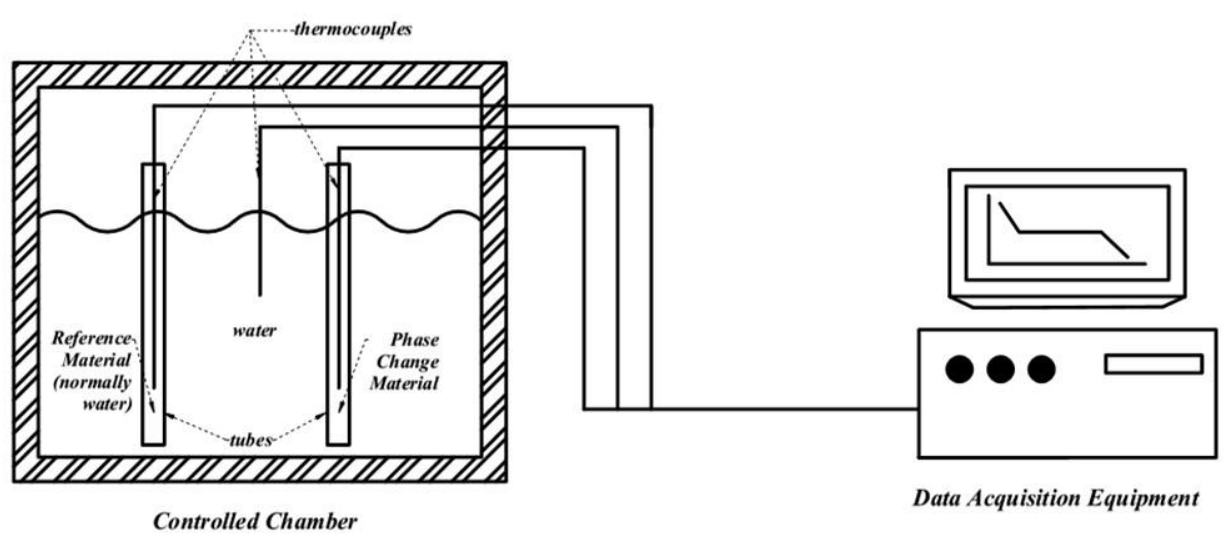

236

237

238 small sub-cooling degree of $0.2^{\circ} \mathrm{C}$ in the developed sample.
Figure 4: Schematic setup for T-history method

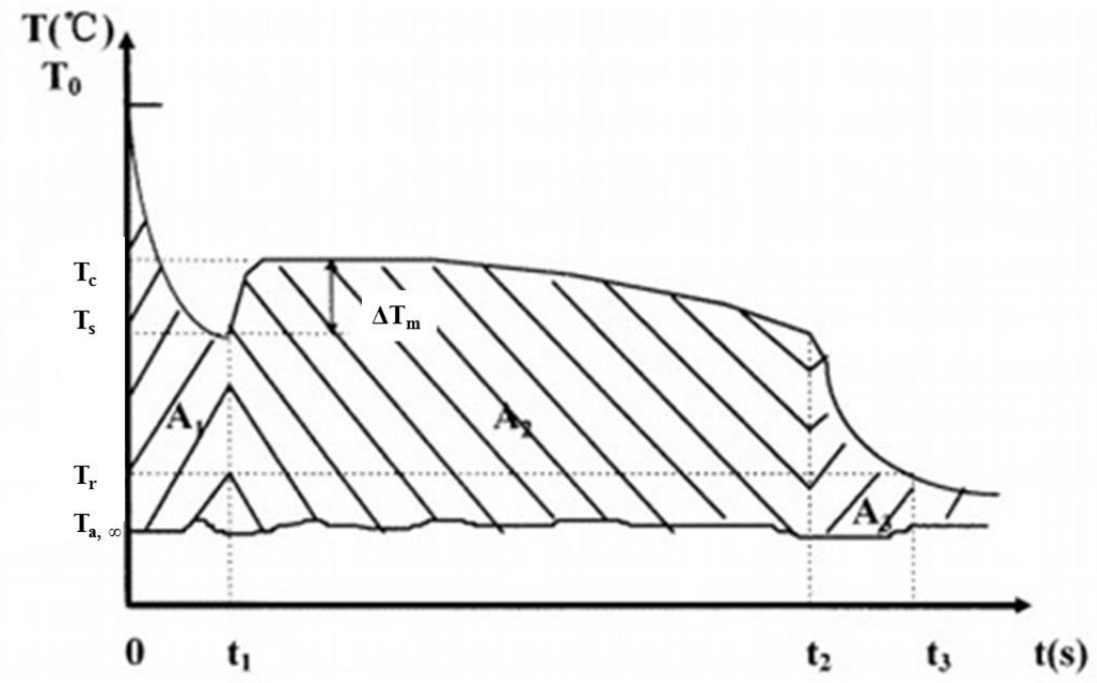

Figure 5: A typical T-history curve of PCM [26] 


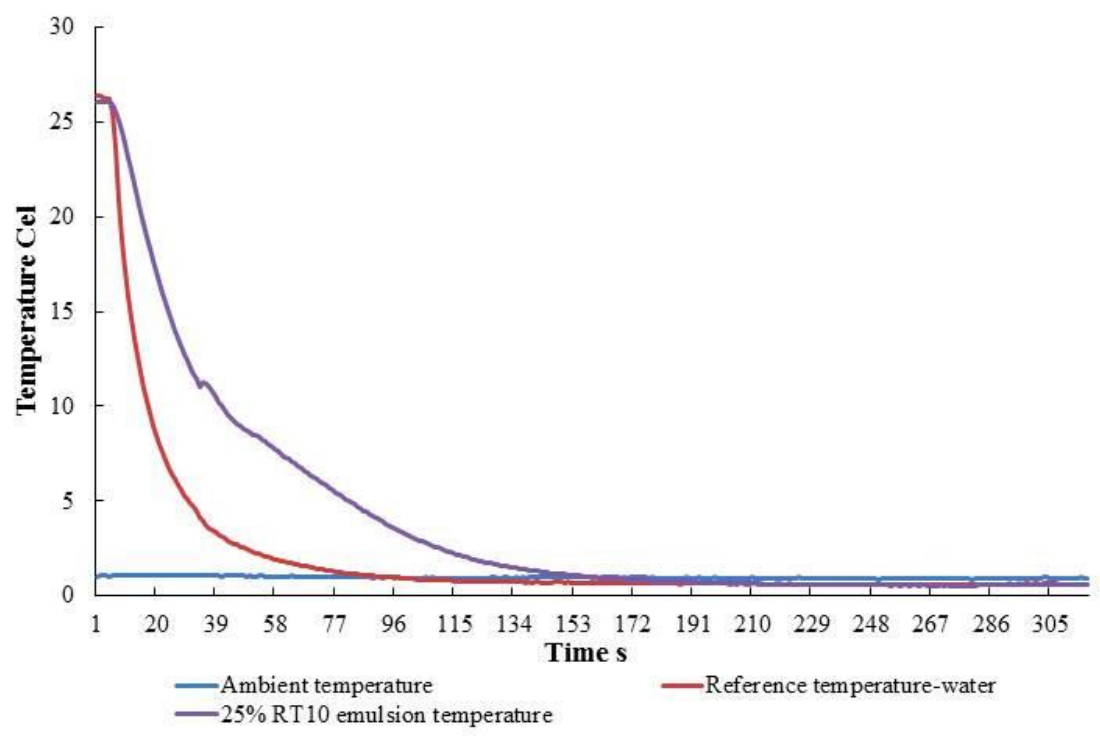

Figure 6: T-history curve of PCE-10

\section{$248 \quad 3.5 \quad$ Viscosity Test}

249 Kinexus $\mathrm{Lab}^{+}$Rotational Rheometer was used to determine the viscosity of PCE-10. The

250 plate diameter is $50 \mathrm{~mm}$, the cone diameter is $50 \mathrm{~mm}$, and the cone angle is $1^{\circ}$. Fig. 7

251 illustrates the relationship between viscosity and shear rate for the developed $\mathrm{PCME}$ at $25^{\circ} \mathrm{C}$

252 and $10^{\circ} \mathrm{C}$. The emulsion is a pseudo-plastic fluid and shows a shear thinning behaviour. The

253 viscosity of the emulsion reduced rapidly with increasing shear rate but stabilised at around

$25413 \mathrm{mPas}$ after $600 \mathrm{~s}^{-1}$. However, the viscosity appears quite high since it is about 13 times

255 higher than that of water. 


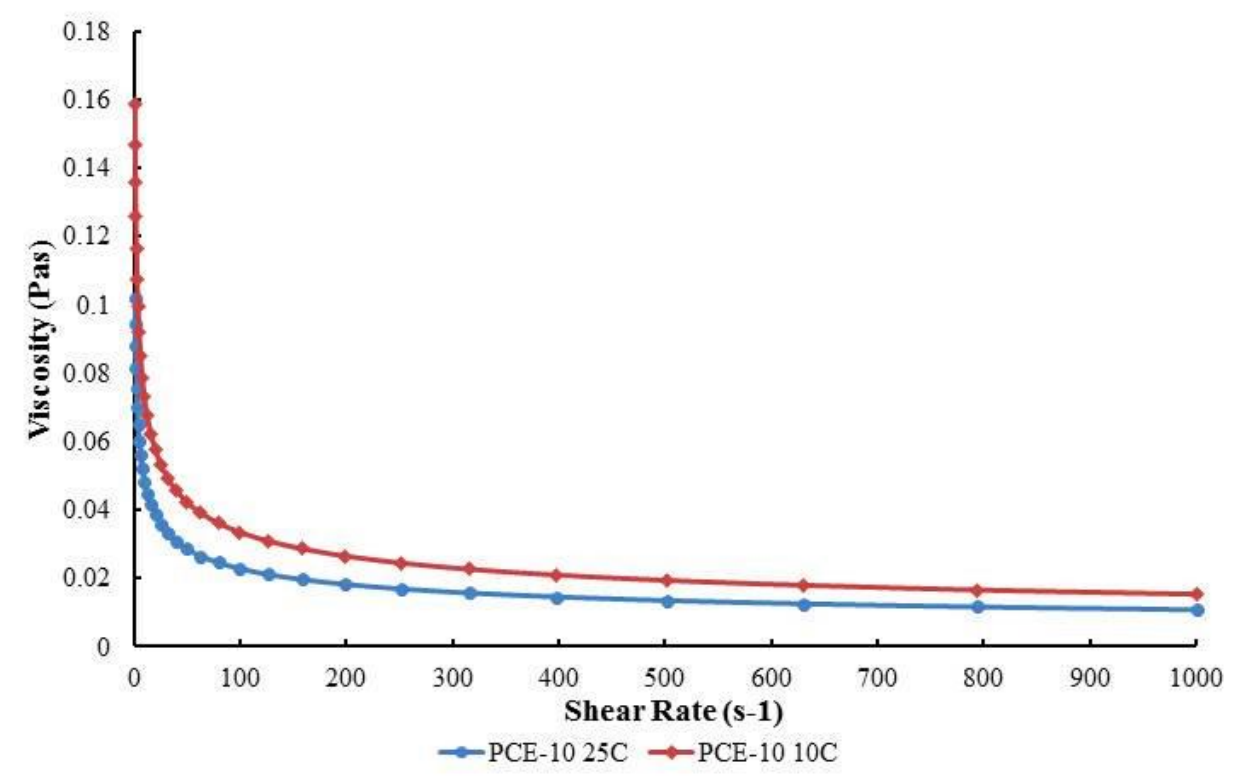

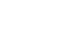

Figure 7: Relationship between viscosity and shear rate for PCE-10 at 10 and $25^{\circ} \mathrm{C}$

The non-Newtonian behaviour can be described using Ostwald Equation:

$$
\eta=K \times \gamma^{n-1}
$$

Where, $\eta$ is the viscosity, $\gamma$ is the shear rate. $K$ and $n$ are coefficients which can be determined with a rheometer. The coefficient $\mathrm{n}$ is the flow behaviour index of a fluid which characterizes its degree of non-Newtonian behaviour. The greater the divergence of $\mathrm{n}$ from unity in either direction, the more non-Newtonian is the fluid. For Newtonian fluids, $\mathrm{n}=1$ and for pseudo-plastic fluids $\mathrm{n}<1$. The coefficient $\mathrm{K}$, flow consistency index, defines the fluid's consistency. The larger the value of $\mathrm{K}$, the thicker is the fluid.

The coefficients $\mathrm{K}$ and $\mathrm{n}$ of PCE-10 were obtained by interpreting the curves in Fig. 7 with the Ostwald Equation Eq. (5). The obtained $\mathrm{K}$ and $\mathrm{n}$ are shown in Tab. 8 Table 8: Coefficients K and $\mathrm{n}$ of PCE-10

\begin{tabular}{ccc}
\hline $\mathrm{T}$ & $\mathrm{K}$ & $\mathrm{n}$ \\
\hline$\left({ }^{\circ} \mathrm{C}\right)$ & 0.1887 & 0.662 \\
25 & 0.102 & 0.675 \\
\hline
\end{tabular}




\subsection{Stability Test}

$274 \quad$ Non-cycling mode

275 The emulsions were stored in containers made of glass at room temperature. The test was 276 carried out at a room temperature through visual inspection and over periodic number of days.

277 As presented in Fig. 8, separation started to occur after 90 days of storage and by the end of 278270 days there was a clear separation between the upper and lower layers. This phenomenon 279 is called creaming and it is caused by the fact that paraffin has a lower density than water.

280 Creaming is the movement of oil droplets under gravity or in a centrifuge to form a 281 concentrated layer at the top of an oil-in-water emulsion. Particle size distribution of sample 282 was tested at the end of the storage period. The result shows a value of $3.41 \mu \mathrm{m}$ (see Fig. 9) at 283 the end of 270 days storage as compared with the original value of $3.14 \mu \mathrm{m}$. This indicates the 284 presence of oil droplets coalescence.

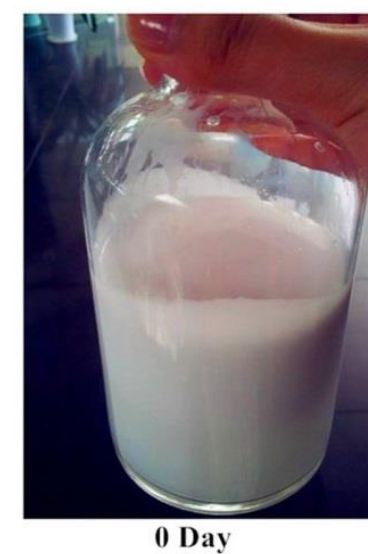

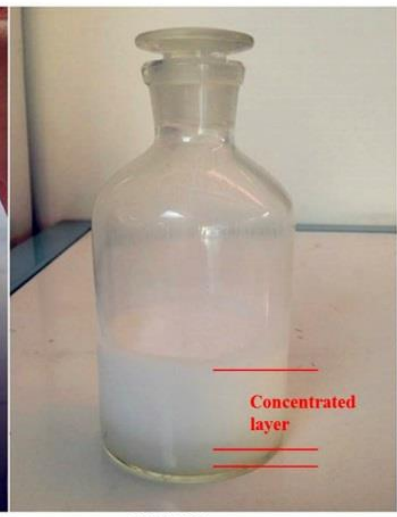

120 Days

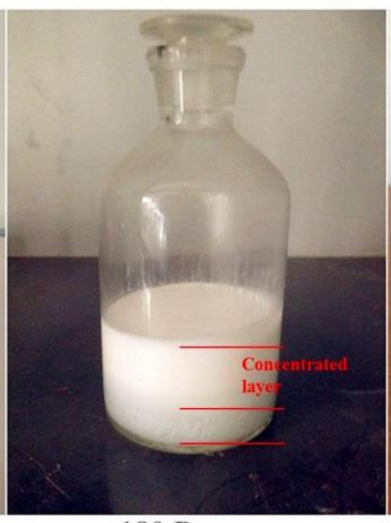

180 Days

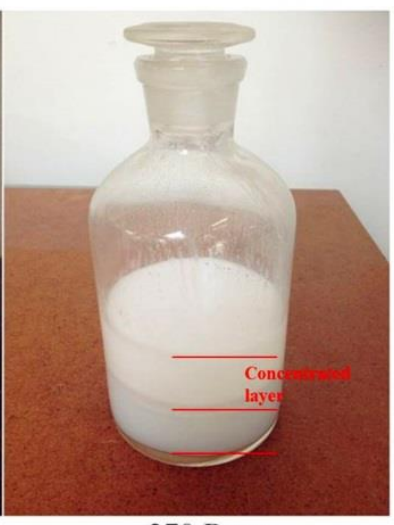

270 Days

Figure 8: Phase separation of emulsion 


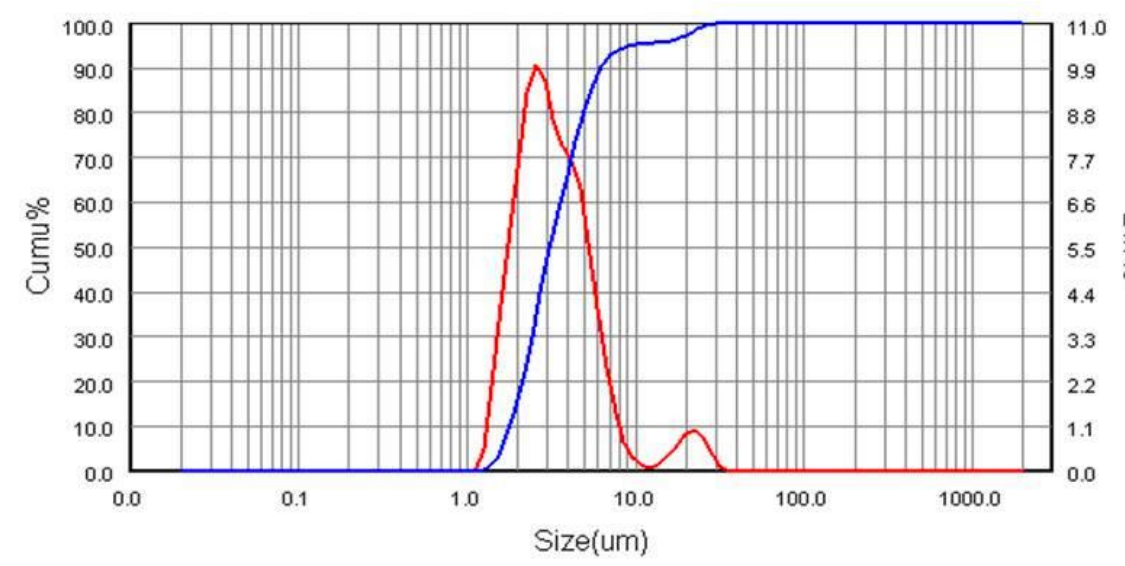

\begin{tabular}{|c|c|}
\hline Diam um & Percent \\
\hline 1.179 & 0.00 \\
\hline 1.712 & 7.30 \\
\hline 2.486 & 31.85 \\
\hline 3.611 & 60.58 \\
\hline 5.245 & 83.12 \\
\hline 7.617 & 93.62 \\
\hline 11.060 & 95.42 \\
\hline 16.060 & 95.97 \\
\hline 23.330 & 98.49 \\
\hline 33.890 & 100.00 \\
\hline
\end{tabular}
and maintained the heat capacity after the test.

\section{Cycling mode} of the base material (RT10) from the emulsion.

Figure 9: Particle sizing of PCE-10 after 270-day storage

The stability of the sample was examined after being subjected to a number of thermal and mechanical loadings. The test rig as illustrated in Fig. 10, consists of a storage tank, a heat exchanger and a circulating pump. The sample was initially cooled down from $25^{\circ} \mathrm{C}$ to $5^{\circ} \mathrm{C}$ and then reheated to $15^{\circ} \mathrm{C}$. After 500 cycles, a clear layer of oil was observed (i.e. oiling-off phenomena) as shown in Fig. 11 at the surface of the sample which was a sign of separation

The droplet size distribution, viscosity and thermal properties of the samples were then analysed and compared with the data before cycling. As shown in Fig. 12, there was a slight increase in viscosity from $13 \mathrm{mPas}$ to $16 \mathrm{mPas}$ at $500 \mathrm{rpm}$. The droplet size also increased slightly from the original size of $3.14 \mu \mathrm{m}$ to $3.93 \mu \mathrm{m}$ (see Fig. 13). The latent heat of fusion was reduced from 30.5 to $29.9 \mathrm{~kJ} \mathrm{~kg}^{-1}$ as illustrated in Fig. 14. This was attributed to the fact that when the emulsion was heated above the melting point, the crystallized droplets melted and fused together thus leading to coalescence and oiling-off at the surface of the emulsion. Although some changes were observed in the properties, the emulsion remained in dispersion 


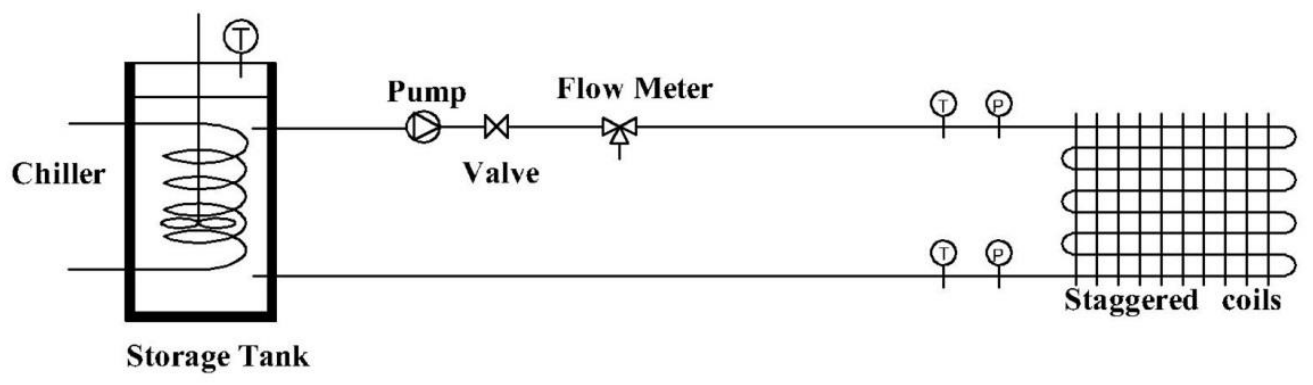

Figure 10: Schematic diagram of the test rig

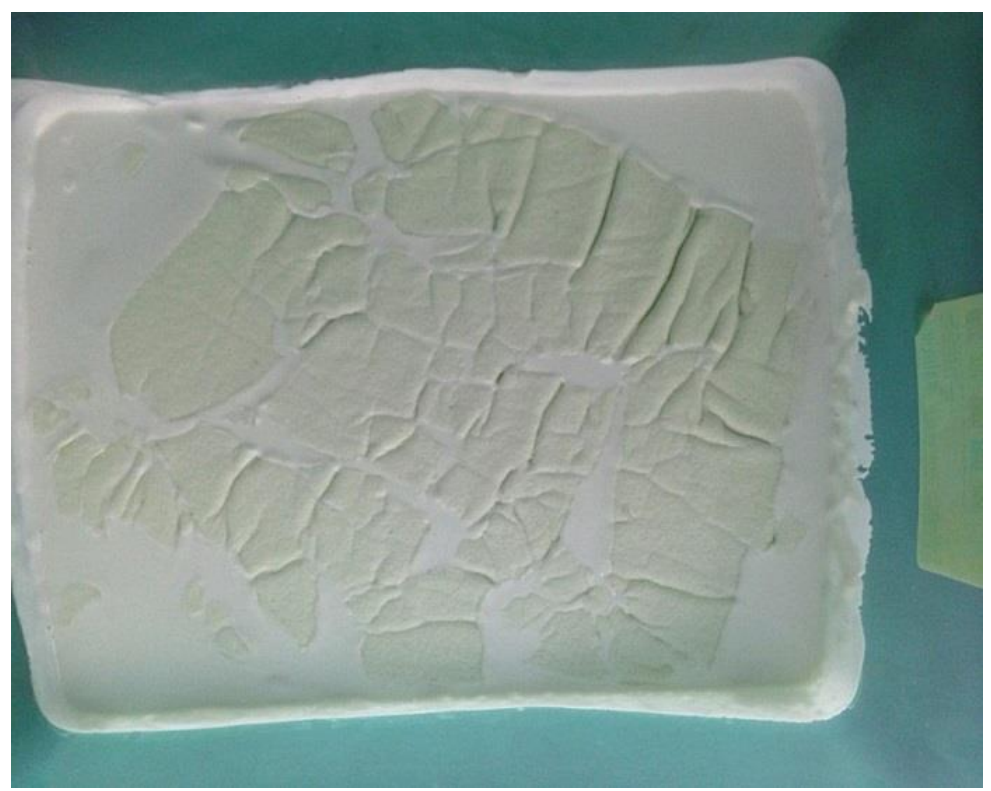

Figure 11: Oiling-off phenomena of PCE-10

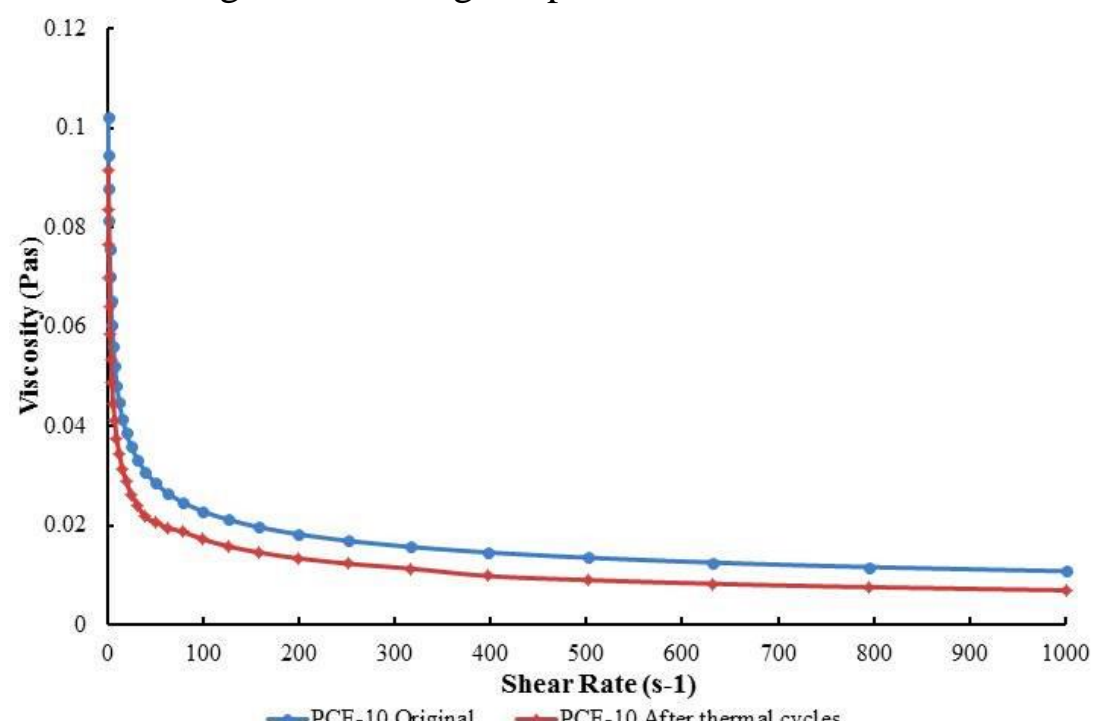

$\rightarrow$ PCE-10 Original $\rightarrow$ PCE-10 After thermal cycles

Figure 12: Rheological behaviour after and before thermal-mechanical cycles 
317

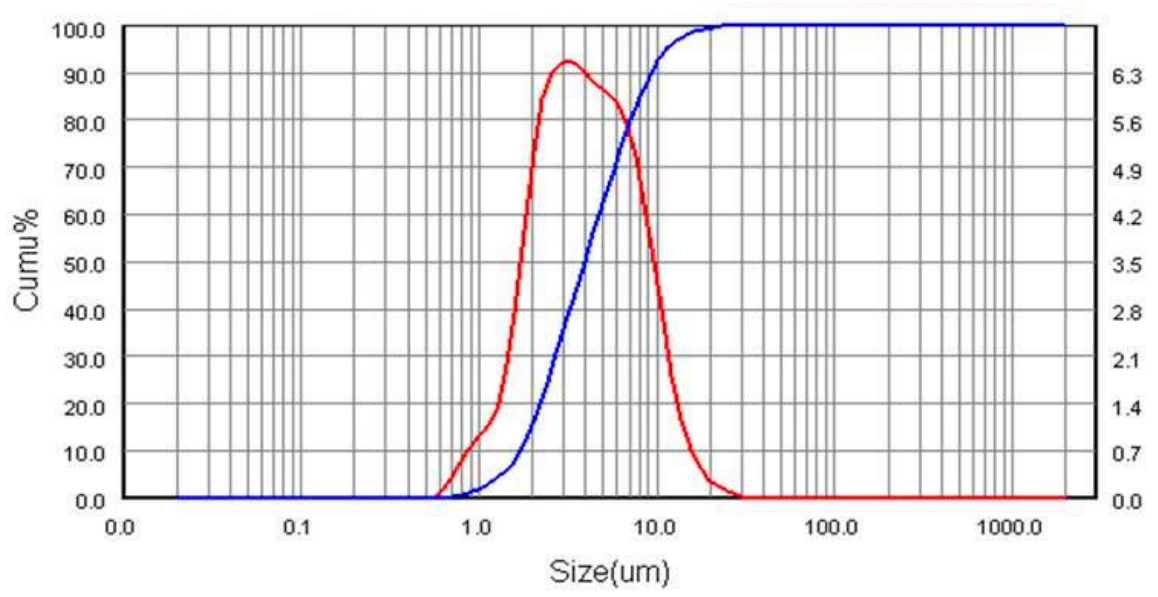

\begin{tabular}{|c|c|}
\hline Diam um & Percent \\
\hline 0.574 & 0.00 \\
\hline 0.891 & 1.27 \\
\hline 1.383 & 5.29 \\
\hline 2.147 & 18.31 \\
\hline 3.333 & 41.19 \\
\hline 5.175 & 64.12 \\
\hline 8.034 & 84.70 \\
\hline 12.470 & 96.47 \\
\hline 19.360 & 99.49 \\
\hline 30.060 & 100.00 \\
\hline
\end{tabular}

Figure 13: Laser Particle sizing after 500 thermal mechanical cycles

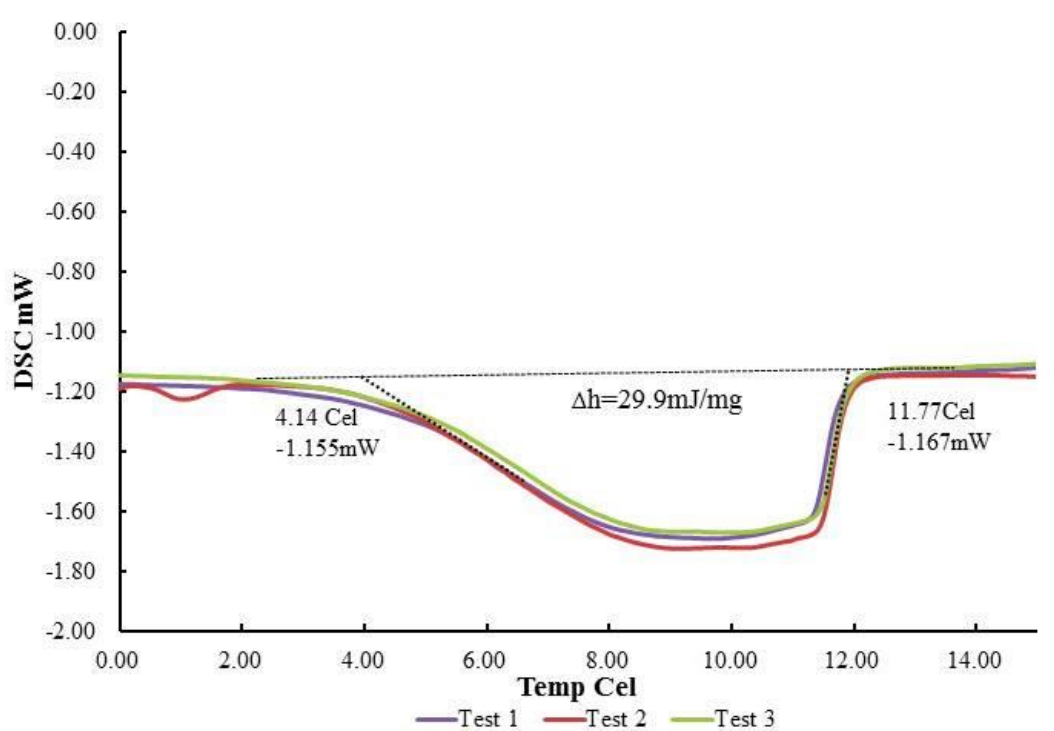

\section{Conclusion}

Figure 14: DSC curves of PCE-10 after 500 thermal mechanical cycles

In this paper, a novel paraffin-water emulsion (PCE-10) has been developed based on an organic paraffin material called RT10. In order to achieve good level of stability in the emulsion, the HLB method was used to obtain an optimum surfactant blend consisting of two selected surfactants (Tween 60 and Brij 52). Analysis of the thermophysical properties revealed the particle size of the PCE-10 sample to be $3 \mu \mathrm{m}$ with a storage heat capacity of almost twice as much as that of water and with a negligible level of sub-cooling. The PCE-10 also achieved a good level of storage stability for 9 months and was able to withstand over 
particle size and heat storage capacity.

found to be about $30 \%$ lower than the value for water and could influence heat transfer.

335 Further enhancements of these thermophysical properties are therefore recommended.

\section{Reference}

[1] T. Hasenöhrl, "An Introduction to Phase Change Materials as Heat Storage Mediums," Sweden2009.

[2] W. Zhong, "Building air conditioning energy consumption and energy saving measures in China," MSc Master thiese, Environment engineering, MSc Chongqing University unpublished, 2004.

[3] C. Pollerberg and C. Dotsch, "Phase changing slurries in cooling and cold supply networks," in 10th International Symposium on District Heating and Cooling, 2006.

[4] Y. Xu, "Study the saving energy method for fan-coil unit system," MSc Master thiese, Construction and Civil Engineering, Xi,an University of Architecture and Technology, unpublished, 2005.

[5] P. Zhang and Z. W. Ma, "An overview of fundamental studies and applications of phase change material slurries to secondary loop refrigeration and air conditioning systems," Renewable and Sustainable Energy Reviews, vol. 16, pp. 5021-5058, 2012.

[6] L. Huang, E. Günther, C. Doetsch, and H. Mehling, "Subcooling in PCM emulsions-Part 1: Experimental," Thermochimica Acta, vol. 509, pp. 93-99, 2010.

[7] L. Royon and G. Guiffant, "Heat transfer in paraffin oil/water emulsion involving supercooling phenomenon," Energy Conversion and Management, vol. 42, pp. 2155-2161, 2001.

[8] J. Wang, "Ruuning cost analysis for water source heat pump air conditioning," $H V \& A C$, vol. 1, pp. 63-66, 2004.

[9] H. Xu, R. Yang, Y. Zhang, Z. Huang, J. Lin, and X. Wang, "Thermal physical properties and key influence factors of phase change emulsion," Chinese Science Bulletin, vol. 50, pp. 188193, 2005.

[10] P. Schalbart, M. Kawaji, and K. Fumoto, "Formation of tetradecane nanoemulsion by lowenergy emulsification methods," International Journal of Refrigeration, vol. 33, pp. 1612$1624,2010$.

[11] J. Vilasau, C. Solans, M. J. Gómez, J. Dabrio, R. Mújika-Garai, and J. Esquena, "Stability of oil-in-water paraffin emulsions prepared in a mixed ionic/nonionic surfactant system," Colloids and Surfaces A: Physicochemical and Engineering Aspects, vol. 389, pp. 222-229, 2011.

[12] L. Huang, M. Petermann, and C. Doetsch, "Evaluation of paraffin/water emulsion as a phase change slurry for cooling applications," Energy, vol. 34, pp. 1145-1155, 2009.

[13] Rubitherm Technologies GmbH. see: http://www.rubitherm.com.

[14] L. Huang, "Paraffin Water Phase Change Emulsion for Cold Storage and Distribution Applications," PhD, Fraunhofer Institute UMSICHT, Ruhr-University Bochum, Electronic publication, 2009.

[15] L. Huang, P. Noeres, M. Petermann, and C. Doetsch, "Experimental study on heat capacity of paraffin/water phase change emulsion," Energy Conversion and Management, vol. 51, pp. 1264-1269, 2010. 
376 [16] F. Zhao, Petrol Chemistry. Beijing: China University of Petroleum Press, 1989.

377 [17] I. Americas, The HLB system a time-saving guide to enulsifier selection. Wilmington, Delaware, US: chemmunique, 1987.

[18] K. Zhang, R. Li, Y. Lu, and P. Shang, "HLB and Surfactant selection," Journal of Shijiazhuang Vocational Technology Institute, vol. 16, pp. 20-22, 2004.

[19] K. Golemanov, S. Tcholakova, N. D. Denkov, and T. CGurkov, "Selection of Surfactants for Stable Paraffin-in-Water Dispersions, undergoing Soild-Liquid Transition of the Dispersed Particles," Langmuir, vol. 22, pp. 3560-3569, 2006.

[20] B. Wang, Y. Zhang, and D. Sun, "Preparation and application of wax emulsion," Shandong Chemical Industry, vol. 33, pp. 14-17, 2004.

[21] J. Wang and T. Zhang, "The anomalous rheological properties of wax miniemusion with mixed emulsifier," Journal of Shandong institute of light industry, vol. 11, pp. 12-14, 1997.

[22] J. Wang, "Preparation and properties of paraffin miniemulsion," Journal of Shandong institute of light industry, vol. 11, pp. 24-27, 1997.

[23] L. L. Schramm, "Emulsion, foams and suspensions," Weinheim: Wiley-VCH Verlag Gmbh \& Co, 2005.

[24] S. D. Sharma and K. Sagara, "Latent Heat Storage Materials and Systems: A Review," International Journal of Green Energy, vol. 2, pp. 1-56, 2005.

[25] X. X. Zhang, Y. F. Fan, X. M. Tao, and K. L. Yick, "Crystallization and prevention of supercooling of microencapsulated n-alkanes," Journal of Colloid and Interface Science, vol. 281, pp. 299-306, Jan 152005.

[26] Y. Zhang, Y. Jiang, and Y. Jiang, "A simple method, the T-history method, of determining the heat of fusion, specific heat and thermal conductivity of phase-change materials," Measurement and Science Technology vol. 10, pp. 201-205, 1999. 